\title{
What do we know about mathematics teacher education? What evidence do we have? What comes next?
}

\author{
Dina Tirosh
}

Published online: 10 April 2009

(C) Springer Science+Business Media B.V. 2009

Assume that you are preparing yourself for an important meeting at your university with many researchers from different domains. You are invited as a researcher in mathematics teacher education. The invitation specifies that in this meeting, each researcher will be asked to address, in no more than 15 minutes, the following three issues:

1. What are the main publications in your domain?

2. What are the main issues in your domain?

3. Describe two main challenges for your research domain in the upcoming 5 years.

Please take some time to think about each of these issues before continuing.

In this editorial I first describe my attempt to address these issues. Then, I briefly relate to each of the four articles that constitute this issue. I end with personal notes.

The first issue (What are the main publications in your domain?) seems relatively easy. I shall mention some journals including the Journal of Mathematics Teacher Education, Educational Studies in Mathematics, the Journal for Research in Mathematics Education, the Journal of Mathematical Behavior, and the International Journal of Science and Mathematics Education. I shall also refer to the main handbooks that were published in mathematics education in the last years, including the four volumes of the International Handbook of Mathematics Teacher Education (Wood 2008), the Second Handbook of Research on Mathematics Teaching and Learning (Lester 2008), The Handbook of International Research in Mathematics Education (English 2008) and the Second International Handbook of Mathematics Education (Bishop et al. 2003). Then, I shall mention some books, for instance, the recently published books in Springer's series of mathematics teacher education (e.g., Clarke et al. 2009) and several books and articles on effective professional development (e.g., Clarke 1994; Loucks-Horsley et al. 1998).

The second issue (What are the main issues in your domain?) is more complicated. I shall certainly discuss the importance of mathematics discipline knowledge and of other forms of mathematical knowledge (e.g., pedagogical content knowledge) for teaching. I shall also describe the vital role of affect (e.g., motivation, self-efficacy) and beliefs (about

D. Tirosh $(\bowtie)$

Tel Aviv University, Tel Aviv, Israel

e-mail: dina@post.tau.ac.il 
mathematics, about learning mathematics, about teaching mathematics) in mathematics teaching. Another central issue that I shall certainly focus on is the professional development of mathematics teachers. Here I shall describe some major stages in teacher growth, effective types of prospective as well as practicing mathematics teacher education, and perhaps some successful examples (e.g., Fennema et al. 1996). Time will not permit discussing other issues.

The third issue (Describe two main challenges for the upcoming 5 years in your domain) leads to reflection on the accumulated body of knowledge in mathematics teacher education and on the nature of evidence that supports the major claims. I shall certainly call for more attention to the following two issues.

\section{Developing and implementing reliable research designs and research tools}

Disturbing though it is, it is commonly said that in education, one can always find studies that support a certain claim while other studies will reject that same claim. Our new, emerging field, like many other fields, strives to develop a coherent and consistent body of knowledge. Developing and implementing reliable research designs and research tools is now both possible and necessary. This, in my opinion, is a major aim of the community of mathematics teacher educators in the coming years.

\section{Studying the impact of organizational issues on the relationship between mathematics teaching and mathematics learning}

The teacher is often viewed as the key factor in determining classroom practice and learning processes. In my opinion, much more attention should be given to studying organizational issues such as the nature of assessment, whether or not the curriculum is mandatory, the role of the cultural context and the schools. These elements deserve more attention as they impact on various aspects of classroom practice (e.g., the choice of textbooks, the use of technology, and the socio-mathematical norms) and of the learning process. As teacher educators as well as researchers of teacher education, investigating and promoting change in teacher practice ought to be done in consideration of the organizational issues mentioned above. This is a major challenge to our community.

The four articles that are published in this issue of JMTE (JMTE 12.3) address the above main challenges for mathematics teacher education in various ways. Here I show how the first two articles contribute to the first challenge and the third and fourth articles to the second. Each of these articles contributes to other issues that are of importance to mathematics teacher education.

The first article "Instructional practices related to prospective elementary teachers' motivation for fractions" by Kristie Jones Newton focuses on measuring a relatively neglected aspect of affect in mathematics teacher education. Newton studies prospective elementary teacher' motivation for a specific domain in mathematics (and not for mathematics in general). She measures prospective elementary teachers' motivation for working with fraction before and after taking a course designed to promote mathematical understanding of the topics that the prospective teachers will be teaching (fractions was a major topic that was dealt with throughout the course). Newton focuses on three aspects of motivation: value; self concept of ability; and anxiety. The main findings are that after the course, students' ratings of the value of fractions and of their self-concept of ability 
increased while anxiety decreased. She also reported that reform practices are associated with lowered anxiety.

A main contribution of this study is the development of a research tool to measure the motivation to a specific, mathematical content. More studies are needed to measure various aspects of motivation of prospective teachers to other, mathematical domains (e.g., geometry) and to identify practices that promote teachers' motivation as well as their mathematical understanding.

A main aim of the article on "Prospective middle school mathematics teachers' reflective thinking descriptions of their students' thinking and interpretations of their teaching," by Amanda Jansen and Sandy Spitzer, is to identify practices that support the development of prospective teachers' reflective thinking skills. Jansen and Spitzer describe variations among prospective teachers' descriptions of students' thinking about how their own teaching affected their students' learning. Jansen and Spitzer report that the prospective teachers used two forms of nuance when describing their students' thinking: (1) identifying students' specific mathematical understandings rather than general claims; and (2) differentiating between individual students' thinking rather than characterizing students as a collective group. They also reported that participants who described their students' thinking with nuance were more likely to interpret their teaching by posing multiple hypotheses for how their instruction affected their students' learning.

An interesting contribution of Jansen and Spitzer's article to the challenge of developing reliable measurement tools is a decision that was taken by the two researchers, during the collection of data, to use a written questionnaire instead of interviews. Jansen and Spitzer clarify that "Initially, we intended for those data to be collected through interviews, but since the interview responses were relatively short, we administered the prompts in the form of a written questionnaire to the rest of the 26 participants." At a first glance, this scenario seems somewhat awkward. We tend to assume that individual interviews result in more information than written questionnaires. Jansen and Spitzer show that this is not always the case.

Marcus Nührenbörger and Heinz Steinbring present three social settings in an article on "Forms of mathematical interaction in different social settings: Examples from students', teachers' and teacher-students communication about mathematics." The first two social settings took place in the same, multi-age class (Grade 1 and Grade 2). Setting 1 presents two young students, one in Grade 1, the other in Grade 2, working together on finding as many addition expressions as possible for the number 8 . The description focuses on a surprising suggestion that was proposed by the younger student. Setting 2 took place at the same class with the same two students and the teacher of the class. It details the discussion of the teacher and the students. Setting 3 describes the reflection of a group of teachers on the first two settings (videos and transcripts of Setting 1 and Setting 2 were used in Setting 3).

A main contribution of Nührenbörger and Steinbring's article is the description and the analysis of the nature of the collegial reflection of the teachers and on their attention to the mathematical as well as to the social subtleties of these interactions. In this and in other publications resulting from the MALIN (Mathematics teaching in multi-age learning groups-interaction and intervention) project, Nührenbörger and Steinbring describe the impact of the specific organizational structure of multi-age learning groups on various aspects of mathematics teaching and learning.

The fourth article, on "Provision of in-service training of mathematics and science teachers in Botswana: Teachers' perspectives" is written by Kim Agatha Ramatlapana. In this article, Ramatlapana describes the perceptions of mathematics and science teachers in Botswana towards in-service provision by the Department of Mathematics and Science 
Education In-service Training unit (DMSE-INSET), whose mandate is to improve the quality of teaching by supporting teachers through training programs that enable them to take ownership of their professional development. Ramatlapana shows that teachers' concerns included the lack of impact of current in-service training programs on the education system, no regular follow-up activities to support the one-off workshops and insufficient skills acquired to sustain the implementation of the strategies solicited by the workshops.

I argued above that investigating and promoting change in teacher practice ought to be done in consideration of organizational issues and that this is a major challenge to our community. Ramatlapana provides specific examples of the consequences of lack of such considerations. One example addresses the training on integrating computers in the classrooms in Botswana. Ramatlapana reports that the participating teachers expressed their frustration at not being able to implement the skills that they acquired in the training on integrating computers in their classes, due to a lack of computers. The teachers recommended avoiding training on topics that cannot be successfully implemented.

I end on two personal notes. I concluded my first editorial in JMTE (Volume 8, Issue 4, on "Proofs and refutations in mathematics teacher education") by encouraging the researchers in our community to contribute to the section on mathematics teacher education around the world. In the last years, we experience more contributions to this, important section of JMTE. The article by Ramatlapana is an example of an article that focuses on "issues of national significance that could be of wider than local or national interest" (this explanation on the nature of the section on mathematics teacher education around the world is provided in the back cover of all the issues of JMTE). I hope that in the coming years, even more articles will be submitted to this section.

Being an editor of a journal is an extremely interesting, yet very demanding mission. I am now standing down as an editor of JMTE after 6 years. I would like to thank Barbara Jaworski for inviting me to act as one of the editors of JMTE and for her on-going support in the personal process of professional growth that I experienced as an editor in the last years. It was a pleasure to work with the other editors: Konrad Krainer, Peter Sullivan, Terry Wood, and recently with Olive Chapman and Anne Cockburn. Special thanks go to the anonymous reviewers-without them it is impossible to carry out this work. Last but not least-my blessings go to Peter Sullivan, the new Editor-in-Chief of JMTE, to the editors of JMTE, and to all the contributors and reviewers-I am certain that our journal will continue to advance the complex, challenging, and fascinating field of mathematics teacher education.

\section{References}

Bishop, A. J., Clements, M. A., Keitel, C., Kilpatrick, J., \& Leung, F. K. S. (Eds.). (2003). Second international handbook of mathematics education. Dordrecht, The Netherlands: Kluwer.

Clarke, D. (1994). Ten key principles from research on the professional development of mathematics teachers. In D. B. Aichele \& A. F. Coxford (Eds.), Professional development of teachers of mathematics (pp. 37-48). Reston, VA: National Council of Teachers of Mathematics.

Clarke, B., Grevholm, B., \& Millman, R. (2009). Tasks in primary mathematics teacher education. New York: Springer.

English, L. D. (Ed.). (2008). Handbook of international research in mathematics education (2nd ed.). New York: Routledge.

Fennema, E., Carpenter, T., Franke, M., Levi, L., Jacobs, V., \& Empson, S. (1996). A longitudinal study of learning to use children's thinking in mathematics instruction. Journal for Research in Mathematics Education, 27, 403-434. doi:10.2307/749875. 
Lester, F. K. (Ed.). (2008). Second handbook of research on mathematics teaching and learning. Charlotte, NC: National Council of Teachers of Mathematics.

Loucks-Horsley, S., Hewson, P. W., Love, N., \& Stiles, K. S. (1998). Designing professional development for teachers of science and mathematics. Thousands Oaks, CA: Corwin.

Wood, T. (2008). International handbook of mathematics teacher education. Rotterdam, The Netherlands: Sense. 